\title{
Original
}

\section{Sand Erosion Behavior of Cast Aluminum Alloys}

\author{
by \\ Gaspar Lito S. Mascardo ${ }^{\dagger}$, Setsuo $\mathrm{Aso}^{\dagger}$, Shoji $\mathrm{Goto}^{\dagger}$ and Yoshinari Komatsu ${ }^{\dagger}$
}

\begin{abstract}
The present paper primarily concerns itself with the use of aluminum alloys for marine applications. The objective of this research is to consider the effects of $\mathrm{Mg}$ concentration, slurry speed, sand grain size, sand-to-water ratio and temperature on the sand erosion resistance of five typical types of aluminum alloys. Quantitative relationships for these were also derived.

Cylindrically-shaped test specimens were attached to a rotating disc immersed in a slurry. Erosion rate was based on the amount of weight loss. $\mathrm{Mg}$ concentration varied depending on the alloy used. Slurry speed varied with the rotation of the disc. Three types of sand were examined and their respective grain sizes determined. Sand-to-water ratio was varied from $0-40 \%$ and tests were conducted using temperatures of $293 \mathrm{~K}$ and $280 \mathrm{~K}$.

From the given conditions, the following conclusions were derived. In Al$\mathrm{Mg}$ type of alloys, the sand erosion resistance increases when the magnesium content increases. The factors affecting erosion rate $\left(W_{k}\right)$ mainly consist of slurry speed (V), sand grain size (F) and sand volume percentage (p). Also, the relationship may be shown in the following formula :
\end{abstract}

$$
\mathrm{W}_{\mathrm{k}}=\mathrm{K} \cdot \mathrm{p}^{1 / 2}\left(\mathrm{~V}^{\mathrm{n}} / \mathrm{F}^{\mathrm{m}}\right)
$$

Key Words : Sand Erosion, Aluminum Alloys, Erosion Rate, Mg Concentration, Slurry Speed, Grain Size, Sand to Water Ratio, Temperature

\section{INTRODUCTION}

Nowadays, aluminum alloys are being used in various places for various applications ${ }^{1}$. This includes its use as a material for marine applications. For marine use, the property of aluminum alloys of being sand-erosion resistant aside from being corrosion-resistant plays an important role. It is in this characteristic that the present study aims to further shed light on the sand-erosion behavior of $\mathrm{Al}-\mathrm{Mg}$ alloys.

The phenomenon called erosion has been known to occur when dealing with coal, iron ore, alumina, silicon carbides, silica sand or in any transport of any fluid mixtures involving both solid and liquid particles mixed in solution. It has been known to occur in pipes, valves, pumps, turbines and a lot more places using industrial materials. It is also a well-known fact that it serves as a cause

\footnotetext{
Received June 8, 1998

$\dagger$ Faculty of Engineering and Resource Science, Department of Materials Science and Engineering, Akita University, 1-1 Tegatagakuencho, Akita 010, Japan
} 
of many serious problems.

Erosion has been defined as a phenomenon wherein mechanical damage occurs on a material's surface due to the repeated bombardment of solid particles. In this definition, erosion differs from other phenomena since fluids play an important role. Furthermore, it is this original, independent role of fluids that gives rise to the damage on the material. Generally, sand erosion deals with the movement of hard particles moving within a stream, the bombardment of these solid particles on the material causes the damage as defined by the phenomenon ${ }^{2}$. Henceforth, when such solid particles are immersed in a liquid medium, the resulting bombardment on the metal surface with the subsequent damage on the material shall be termed as sand erosion.

On an earlier research, the effects of alloy composition and slurry speed on the sand-erosion resistance of aluminum alloys have been investigated. However, a more definitive study was suggested.

It is the objective of this research, therefore, to further examine the effects of slurry speed, temperature, sand-to-water ratio and grain size on the sand erosion resistance of five (5) representative aluminum alloys in seawater and somehow derive quantitative relationships thereon.

\section{EXPERIMENT METHOD}

\section{2-1. Test Piece Preparation}

The five (5) types of specimens used in the present experiment were made from commercial 99.7 $\%$ aluminum, $99.9 \%$ magnesium, Al-25.3mass\% $\%$ i alloy and $\mathrm{Al}-49.56 \% \mathrm{Cu}$ alloy as raw materials. From this, $450 \mathrm{~g}$ of the said material was melted to produce target compositions following JIS standards for Al-3mass $\% \mathrm{Mg}$, Al-7mass\%Mg, Al-10mass\%Mg, Al-7mass\%Si-0.3mass\%Mg, Al-8mass \% Si-3Mass\%Cu-0.3mass\% alloys. Since the composition mainly depended on mass percentages, computations were done to produce the desired alloys.

As indicated by the metal charge calculation, the aluminum, Al-25.3mass\%Si alloy and Al-49.56 mass\% $\mathrm{Cu}$ alloy were placed inside a No. 4 Graphite crucible which was then inserted to the electric furnace cylinder. The electric furnace was heated to a temperature of about $973 \mathrm{~K}$ (occuring approx. 2-3hrs. after switching the power on). Also, a caromel-alomel thermostat is placed directly in the melt. Once the melt temperature reaches $993 \mathrm{~K}$ ( $60 \mathrm{~K}$ above the aluminum melting point of $933 \mathrm{~K}$ ), it was poured to an insulated die ( $\phi 38$ cylinder).

The test pieces are then prepared by cutting off four $100 \mathrm{~mm}$ length rods from the casting as shown in Figure 1. From these rods, the required sand erosion test specimens $(\phi 9.9 \times 75 \mathrm{~mm})$ were then lathed using the facilities of the machine shop. After machining, in order for the test specimens to have an over-all homogeneous surface-finish, a No. 120 and No. 1000 emery paper were used on a polisher to do the final finish.

\section{2-2. Sand Erosion Test}

The sand erosion test apparatus as shown in Figure 2 is a rotary-type test apparatus with a disc holding the test specimens immersed and rotating inside the slurry. This apparatus can easily hold 7 rods installed on the disc. It also possesses the option of having the test temperature and slurry speed adjusted to the desired level.

In this sand erosion test, the actual seawater temperature of $293 \mathrm{~K}$ was considered. The importance of slurry speed, grain size, and sand-to-water ratio as experimental factors and the resulting behavior were examined. 


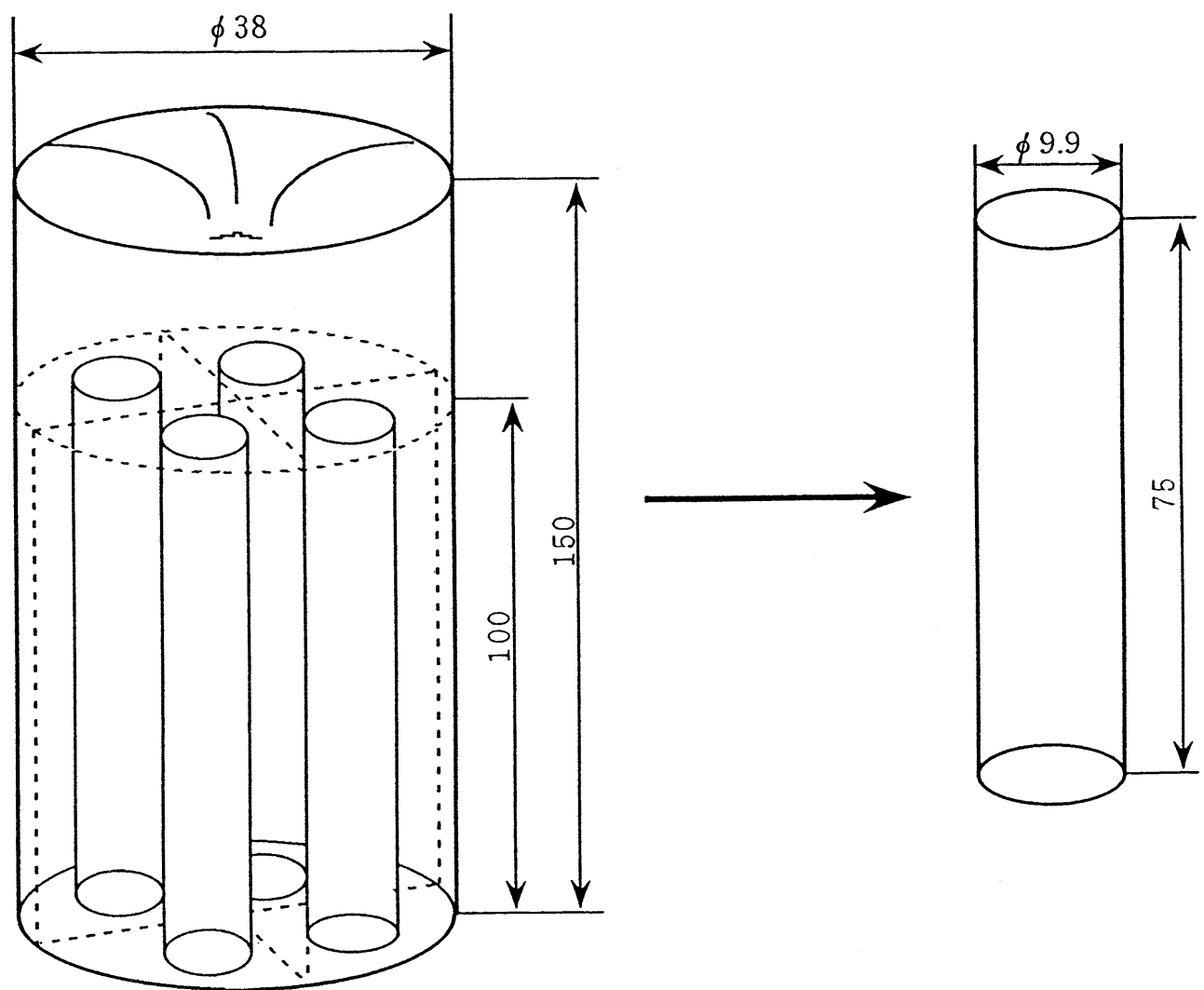

Figure 1. Cutting Layout of Cast Block and Test Specimen Dimensions
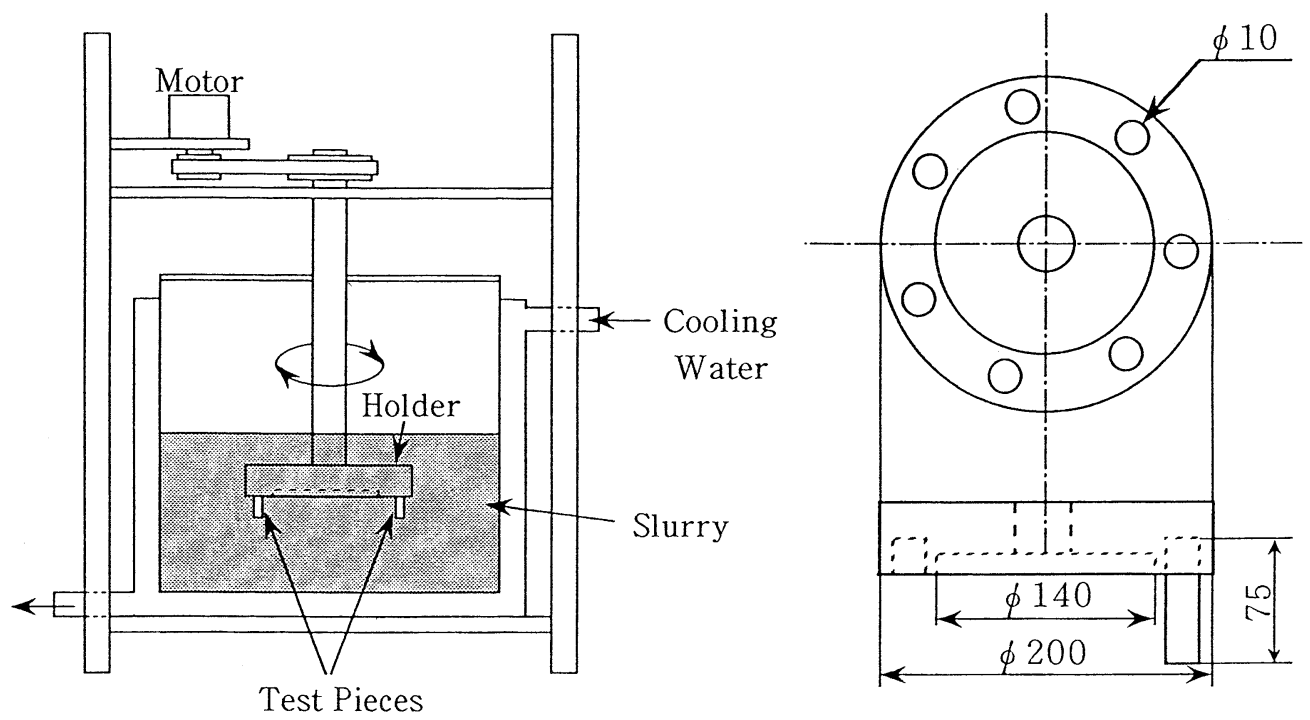

a) Test Equipment

b) Holder

Figure 2. Sand Erosion Test Equipment 
In order to investigate the normal trend of sand erosion, as well as to examine to what degree the addition of magnesium on the aluminum alloy has ; a flattery type of sand was prepared, and using test conditions of ordinary sand-to-water ratio of $4: 6$ and slurry speed of $7.7 \mathrm{~m} / \mathrm{s}(960 \mathrm{rpm})$, the test was conducted.

In investigating the effect of slurry speed, the following test conditions were used. The sand type used was flattery sand, sand-to-water ratio of $4: 6$ was used and slurry speeds of $3.0 \mathrm{~m} / \mathrm{s}(400 \mathrm{rpm})$, $5.2 \mathrm{~m} / \mathrm{s}(660 \mathrm{rpm}), 7.7 \mathrm{~m} / \mathrm{s}(960 \mathrm{rpm}), 9.3 \mathrm{~m} / \mathrm{s}(1150 \mathrm{rpm})$ were alternately conducted.

In investigating the effect of grain size, three types of sand were considered ; namely, sand directly taken from the beach, No. 5 silica sand and flattery sand. Other conditions include the use of sand to seawater ratio of $4: 6$ and a slurry speed of $5.2 \mathrm{~m} / \mathrm{s}(660 \mathrm{rpm})$. From here on, the term "seasand" shall refer to sand taken directly from the beach.

In investigating various sand to water ratios ; seasand was used, the ratios of sand to seawater varied from $0: 10,2: 8,4: 6$; and a slurry speed of $3.9 \mathrm{~m} / \mathrm{s}$ (500 rpm) was taken.

Also, in considering sand erosion resistance at low temperatures, the test temperature was set at $280 \mathrm{~K}$, the type of sand used was seasand, a sand to seawater ratio of $4: 6$ was used, and the test was done at a slurry speed of $5.2 \mathrm{~m} / \mathrm{s}(660 \mathrm{rpm})$. A summary of these test conditions is shown in Table 1.

Table 1. Test Conditions used in the Experiment

Effect of Magnesium

TEST CONDITIONS

\begin{tabular}{|c|c|c|c|c|}
\hline Slurry Speed $(\mathrm{m} / \mathrm{s})$ & Sand: Water & Grain Size (FN※) & Temp (K) & Time (h) \\
\hline 7.7 & $4: 6$ & Flattery Sand (109.0) & 293 & 70 \\
\hline \multicolumn{5}{|l|}{ Effect of Slurry Speed } \\
\hline Slurry Speed $(\mathrm{m} / \mathrm{s})$ & Sand : Water & Grain Size (FN※) & Temp (K) & Time (h) \\
\hline 3.0 & \multirow{4}{*}{$4: 6$} & \multirow{4}{*}{ Flattery Sand (109.0) } & \multirow{4}{*}{293} & \multirow{4}{*}{35} \\
\hline 5.2 & & & & \\
\hline 7.7 & & & & \\
\hline 9.3 & & & & \\
\hline
\end{tabular}

Effect of Grain Size

\begin{tabular}{c|c|c|c|c}
\hline \hline Slurry Speed (m/s) & Sand : Water & Grain Size (FN※) & Temp (K) & Time (h) \\
\hline \multirow{2}{*}{5.2} & \multirow{3}{*}{$4: 6$} & Flattery Sand (109.0) & \multirow{2}{*}{293} & \multirow{2}{*}{35} \\
\cline { 3 - 3 } & & No.5 Silica Sand (67.5) & \multirow{2}{*}{ Seasand (22.0) } & \\
\cline { 3 - 4 } & & & \\
\hline
\end{tabular}

Effect of Samd to Water Ratio

\begin{tabular}{c|c|c|c|c}
\hline \hline Slurry Speed (m/s) & Sand : Water & Grain Size (FN※) & Temp (K) & Time (h) \\
\cline { 2 - 2 } 3.9 & $0: 10$ & & & \multirow{2}{*}{ Seasand (22.0) } \\
\cline { 2 - 2 } & $2: 8$ & & 293 & 35 \\
\hline
\end{tabular}

Effect of Temperature

\begin{tabular}{c|c|c|c|c}
\hline \hline Slurry Speed (m/s) & Sand : Water & Grain Size (FN※) & Temp (K) & Time (h) \\
\cline { 4 - 5 } 5.2 & $4: 6$ & Seasand (22.0) & 293 & 35 \\
\cline { 4 - 5 } & & &
\end{tabular}

$※ \mathrm{FN}$ : The larger the FN, the smaller the grain size. 


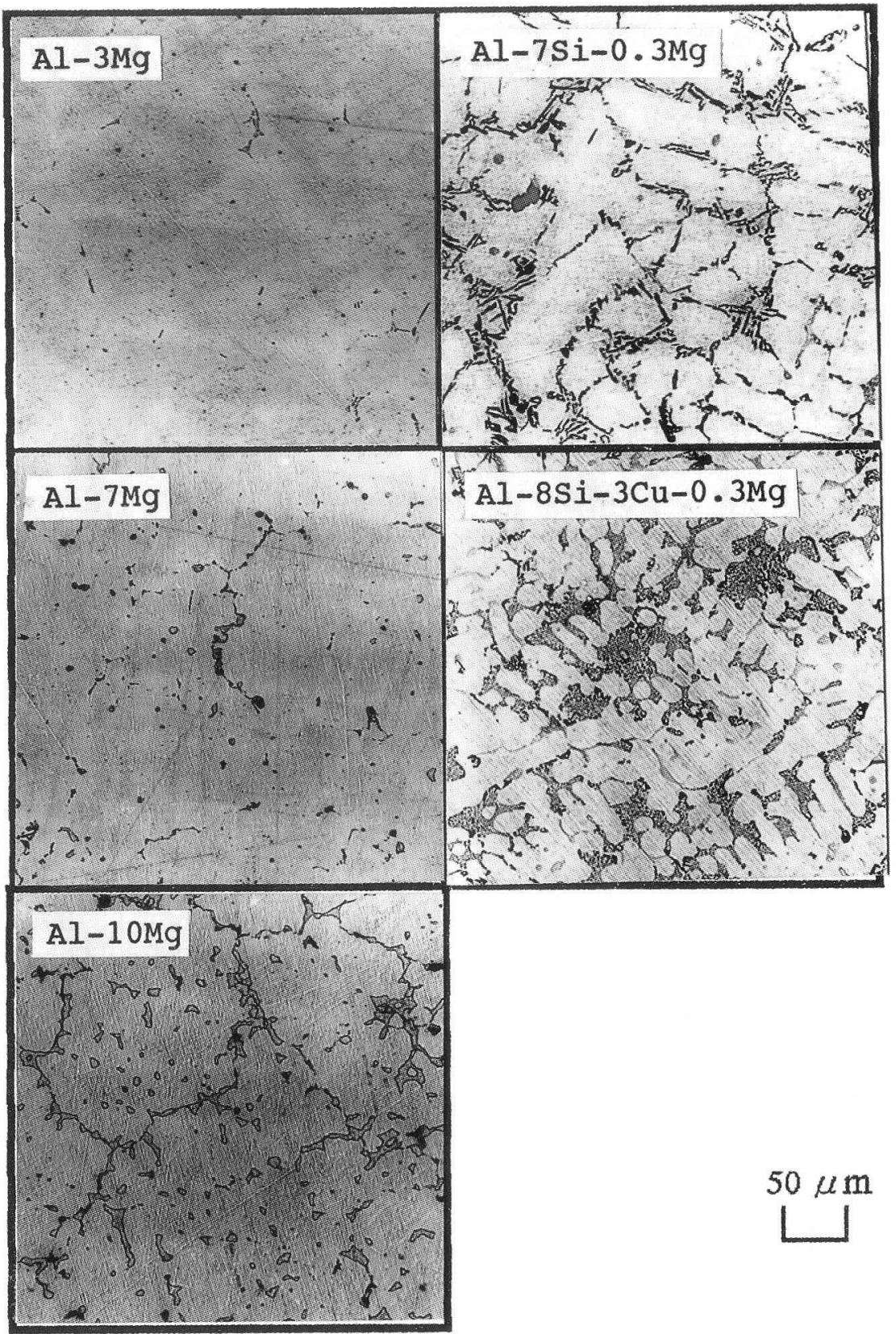

Figure 3. Photomicrographs of the Aluminum Alloys used showing the Effect of Chemical Composition 
In order to evaluate the sand erosion resistance, the amount of weight loss as calculated by the formula given below is used.

$$
\begin{gathered}
\text { Amount of Weight loss }(\%)=\left[\left(\mathrm{W}_{0}-\mathrm{W}_{1}\right) / \mathrm{W}_{0}\right] \times 100 \\
\text { where } \mathrm{W}_{0}: \text { Weight before the test }(\mathrm{g}) \\
\mathrm{W}_{1}: \text { Weight after the test }(\mathrm{g})
\end{gathered}
$$

\section{2-3. Microstructure before Erosion and Surface Observations after Erosion}

The remaining portions of the casting earlier made from the metal die after portions for the test specimens were taken were also gathered. From here, using Emery papers ranging from No. 100 to No. 1500, the surfaces were wet ground. After this, the alumina buffer was used until a mirror-finish was obtained. The as-polished microstructures of the Al-Si-Mg alloy and the Al-Si-Cu-Mg alloy were examined. In the case of the aluminum alloys with varying percentages of $\mathrm{Mg}$, the samples were first etched with a Nitric Acid (10cc) and Ethanol (190cc) etchant before being examined. The resulting photomicrographs are shown in Figure 3. In Al-Mg alloys, the $\beta$ phase in the aluminum solid solution is basically made up of $\mathrm{Al}_{3} \mathrm{Mg}_{2}{ }^{3}$. Also, in Al-Si-Mg alloys and Al-Si-Cu-Mg alloys, both dendrites and eutectic Si structures may be observed ${ }^{4}$. It thereby follows that in $\mathrm{Al}-\mathrm{Mg}$ alloys with low $\mathrm{Mg}$ content, few $\beta$ phase microstructures may be seen ; and in $\mathrm{Al}-\mathrm{Mg}$ alloys with high $\mathrm{Mg}$ content, more $\beta$ phase microstructures may be seen.

The part of the test specimen which succumbed to the fiercest erosion is shown in Figure 4. About $10 \mathrm{~mm}$ from this end was cut for observation using the EPMA.

\section{2-4. Measurement of Grain Size Distribution}

The method used for measuring grain size distribution was based upon JIS Standard Z 2602. This standard is primarily used for measuring the grain size of foundry sands. Now, in order to quantitatively represent the grain size, the grain fineness number is used. The grain fineness number is a number that is representative of the cross-sectional area of the sand grain. The bigger this number is, the smaller the grain.

\section{2-5. Measuring Hardness using Micro-Vickers Hardness}

In measuring the hardness of the cast sample surface which was mirror-finished, five spots were chosen and the Micro-Vickers tester was used to get a hardness reading. The average of the five (5)

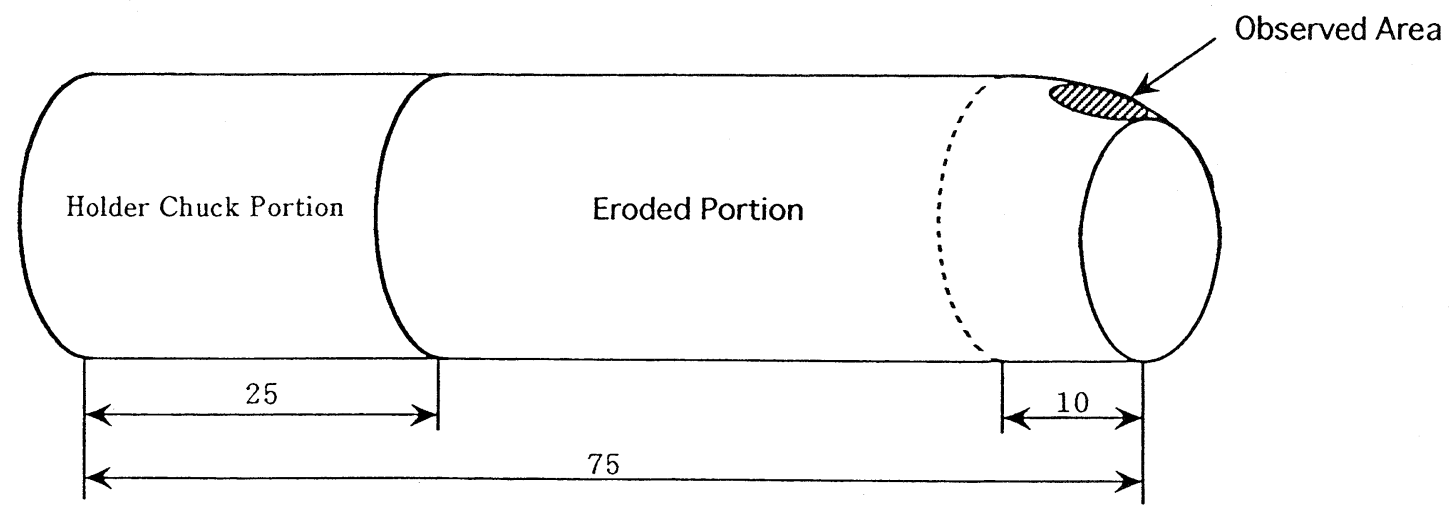

Figure 4. Layout for the Observation of the Aluminum Sand Erosion Test Piece 
readings is the hardness of the material. The load, which must create an indention wherein, the indented surface is somehow homogeneous both at the precipitated phase and at the rest of the material, is 300 grams.

\section{RESULTS AND DISCUSSION}

\section{3-1. Effect of Chemical Composition on the Erosion Rate of Aluminum Alloys}

The effect of alloy composition on the erosion rate of the aluminum alloy used in this sand erosion experiment is shown in Figure 5. For approximately 7 hours after the start of the experiment, the unit time for erosion loss to occur is large; however, from 14 hours to 70 hours later, the unit time for erosion loss to occur becomes smaller, it then tends to exponentially increase.

Also, in the case of Al-Mg alloys, as the magnesium content increases, the sand erosion resistance tends to improve. The reason for this may be viewed from the photomicrograph of the samples shown in Figure 3 ; as the amount of magnesium increases, the amount of $\beta$ phase also increases. It may be reasoned that since the $\beta$ phase is a hard crystal phase, the sand erosion resistance tends to improve. However, in also considering grain size and the sand-to-water ratio, comparing $\mathrm{Al}-7 \mathrm{Mg}$ and $\mathrm{Al}-10 \mathrm{Mg}, \mathrm{Al}-7 \mathrm{Mg}$ exhibits a better sand erosion resistance. Rationalizing this, although the presence of the $\beta$ phase improves the hardness, other factors come about which affects the sand erosion resistance.

\section{3-2. Effect of Slurry Speed on the Erosion Rate of Aluminum Alloys}

The sand erosion apparatus used in the present experiment is a rotating disc type wherein the slurry

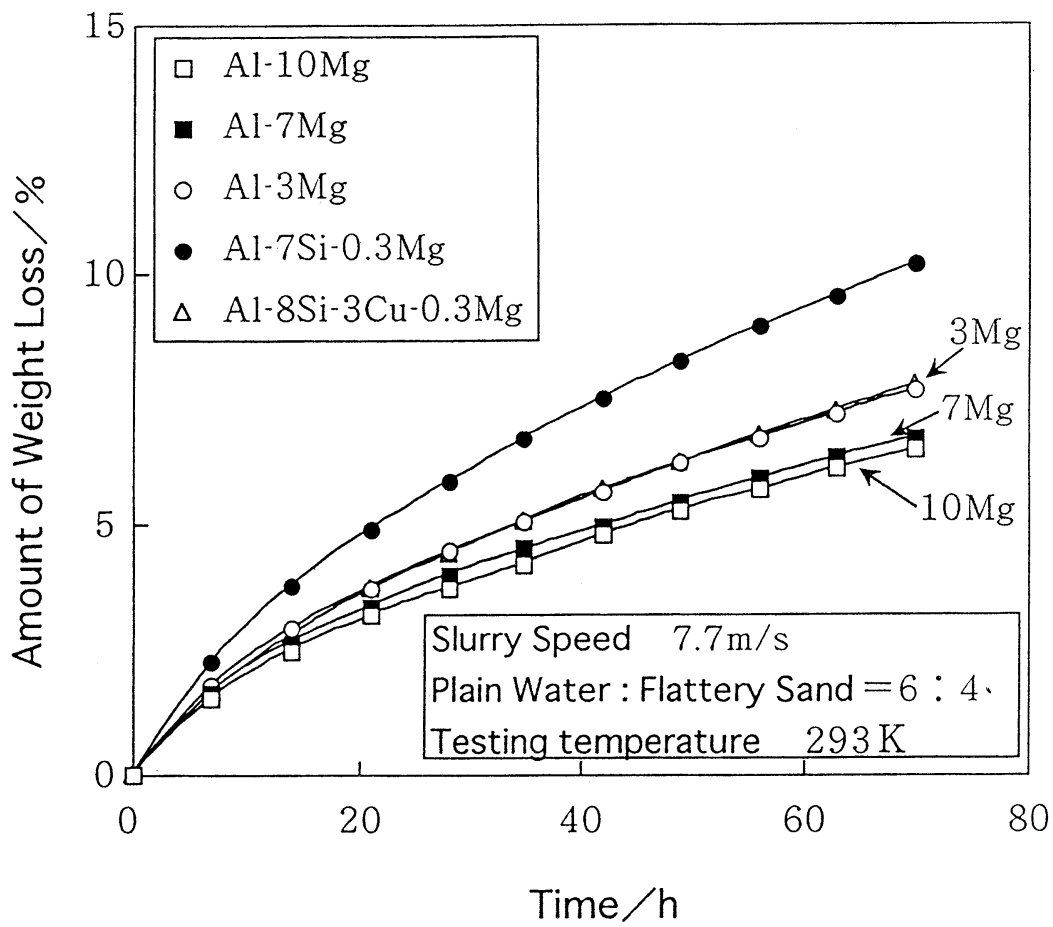

Figure 5. Amount of Weight Loss over a given Time Period 
rotates at the same time as the holder rotates. Naturally, however, the rotation rate of the holder differs from that of the slurry. In order to fully understand the essence of how wear occurs, the resulting data must be examined using the relative speed (slurry speed) shown below.

A relationship between the holder's rotation speed and a waterwheel's rotation speed is plotted from gathered data of holder's rotation speed and the corresponding water-wheel rotation speed.

From here, and from the holder's and water wheel's radius, the unit time per distance travel is taken ; from this difference, the slurry speed is derived. Given that, the holder's rotating radius is $85 \mathrm{~mm}$ and the water wheel's rotating radius is $42.5 \mathrm{~mm}$.

Also, since the measured time is the same both for high speed and low speed, it naturally follows that the distance travelled by the test specimen in the slurry will differ. From this, using the erosion rate given below, the erosion behavior can be evaluated.

$$
\mathrm{W}_{\mathrm{K}}=\mathrm{W}_{\mathrm{L}} / \mathrm{t}
$$

where $W_{K}$ : erosion rate

$\mathrm{W}_{\mathrm{L}}$ : weight loss over a unit distance travelled

$\mathrm{t}$ : time to travel a unit distance

Four slurry speeds namely $3.0 \mathrm{~m} / \mathrm{s}(400 \mathrm{rpm}), 5.2 \mathrm{~m} / \mathrm{s}(660 \mathrm{rpm}), 7.7 \mathrm{~m} / \mathrm{s}(960 \mathrm{rpm})$ and $9.3 \mathrm{~m} / \mathrm{s}(1150 \mathrm{rpm})$ were used. The relation between erosion rate and slurry speed after a 35-hours testing period is summarized on Figure 6. The reason why it was graphed at a 35-hours testing period is ; at a slurry speed of $9.3 \mathrm{~m} / \mathrm{s}(1150 \mathrm{rpm})$, the length of the specimen after 70 hours shortens from the initial length of $75 \mathrm{~mm}$. Also, as the surface area of the erosion surface increases, the amount

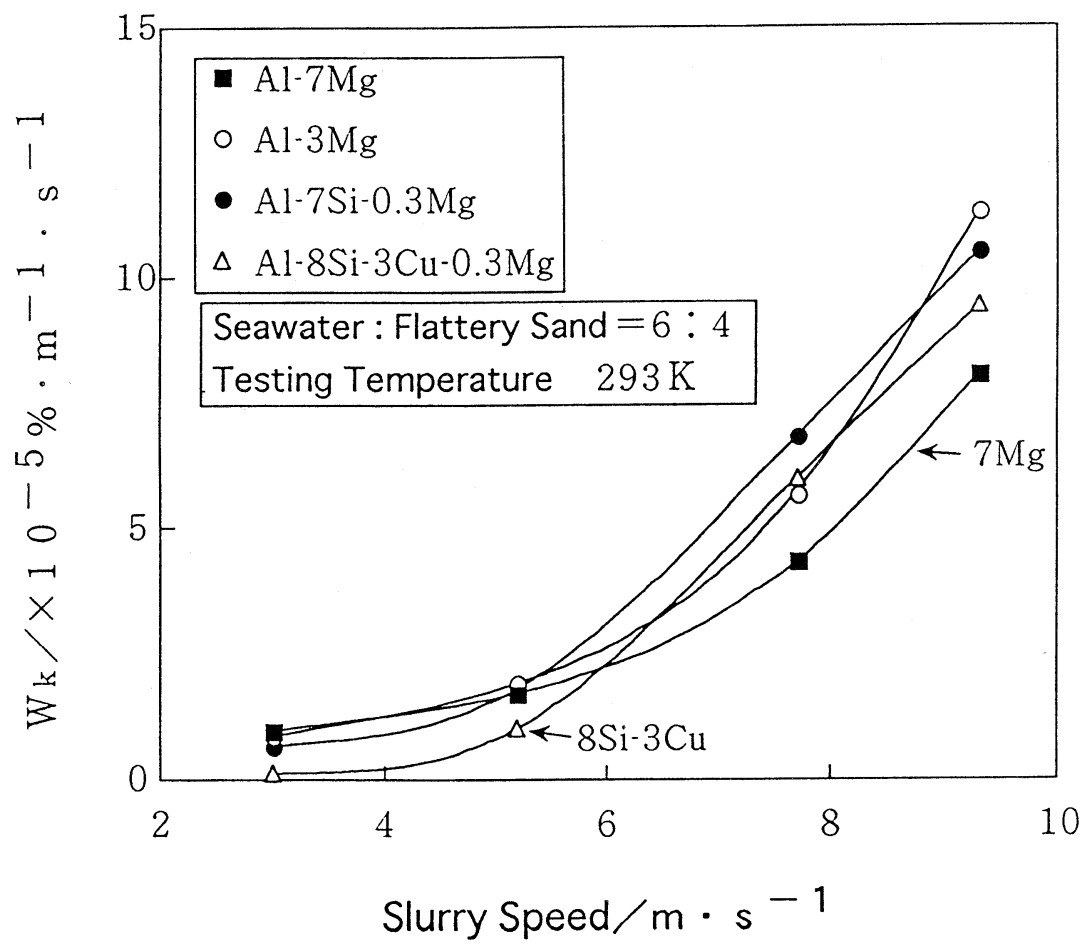

Figure 6. Effect of Slurry Speed on the Erosion Rate 
of weight loss per unit time 14 hours after does not differ. Because of this, data after a 35 hours period was taken as a reference.

\section{3-3. The Start of Wear}

About 7 hours after the start of the test, the amount of weight loss per unit time tends to be constant. As shown in Figure 7a), when the corners of the immersed tip of the cylindrical test piece disappears, the amount of weight loss per unit time drastically increases. This condition is known as the start of wear.

\section{3-4. Change in the Shape of the Test Piece}

In the present research, the choice of 35 hours testing time so as to determine a change in form

a)

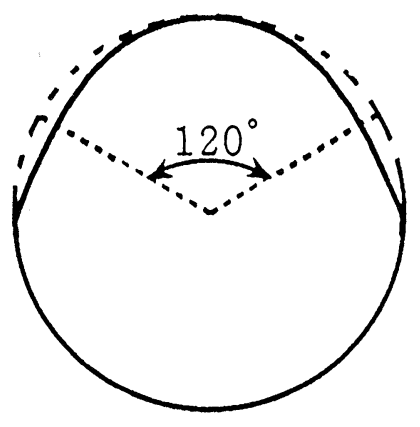

b)

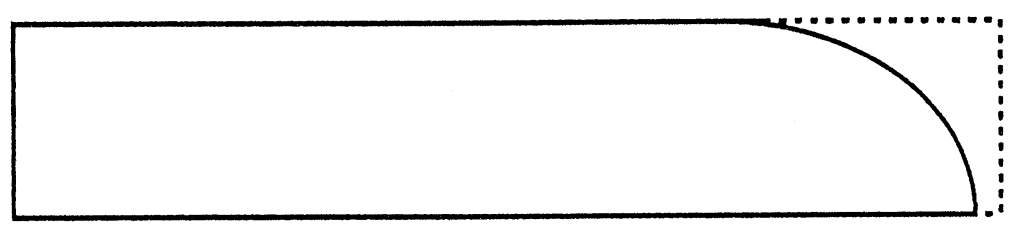

c)

Figure 7. Sectional view showing the change in shape of the test piece 
on the erosion surface has been a matter of usual practice. Thus, in determining to what degree the erosion surface has change may be approximated by the change in shape of the test specimen, as shown in Figure 7b) when the circular cross-section turns into an elongated one. However, even though the erosion occurring within the fluid, which has a higher viscosity and density compared to that of the atmosphere causes a rounding off of nearly $120^{\circ}$, such an environment may still be regarded as having no significant change occurring in the shape of the specimen ${ }^{5}$. Furthermore, as seen in the discussion of Figure 7a), taking into consideration the side view of the specimen, by maintaining the base of the test piece at the start of wear, even though minor portions are taken off, it may still be considered as there is no change in the overall shape. However, as shown in Figure 7c), once a larger portion is eroded, the surface area of the erosion face increases. Also, the final length of the test piece differs from the original length of $75 \mathrm{~mm}$ and may be regarded as a significant change in the shape of the test piece. In the present experiment, a condition wherein there is no significant change in the shape of the test piece is desired.

From here, it can be seen that at low speeds, Al-7Si-3Cu- $0.3 \mathrm{Mg}$ exhibits a better sand erosion resistance while at high speeds, $\mathrm{Al}-7 \mathrm{Mg}$ exhibits a better sand erosion resistance. Furthermore, it can be seen that there lies a difference in the sand erosion resistance of aluminum alloys at low and high speeds.

Using the axes for erosion rate and slurry speed, an equational relationship can be derived. The erosion rate can therefore be shown as :

$$
\mathrm{W}_{\mathrm{K}}=\mathrm{k}_{\mathrm{a}} \cdot \mathrm{V}^{\mathrm{n}}
$$

$$
\begin{aligned}
\text { where } \mathrm{V} & \text { : slurry speed } \\
\mathrm{k}_{\mathrm{a}} & \text { : constant } \\
\mathrm{n} & : \text { index number }(\mathrm{n} \fallingdotseq 2-4)
\end{aligned}
$$

\section{3-5. Effect of Grain Size on the Erosion Rate of Aluminum Alloys}

Up until this time, all the measured data has been based on the use of flattery sand as the type of sand used. Al-Mg alloys, however, are widely used as materials for propellers used in light marine crafts. In order to simulate actual conditions; therefore, measurements on the grain size of actual sand used must be made. To do this, beach sand taken from the seashore was prepared, used and data from this eventually measured.

Since beach sand is rather coarse, the need to confirm whether there is a change in grain size during the course of the sand erosion experiment has to be made. This is done by measuring the grain size distribution before and after the experiment as shown in Figures 8 and 9. From these results, compared to before the experiment, the grain size after the experiment is a little finer. In comparing the test piece (aluminum alloy) with the sand (particularly silica sand), it may clearly be seen that the sand is harder ; the impingement of the sand on the test piece therefore does not cause the sand to become finer rather it is the impingement of the sand particles with similar sand particles which causes this. Since there is no significant difference in the shape of the grain size distribution curve, and since the grain fineness number differs only by about 4 , it is thereby safe to say that no significant change in the grain size is observed. Following the same line of reasoning, similar observations are made on the other sands (No. 5 silica sand and flattery sand).

Similarly related to the conditions on the effect of grain size is the earlier use of $7.7 \mathrm{~m} / \mathrm{s}$ (960 $\mathrm{rpm}$ ) measured at a silica sand to water ratio of $40 \%$. However, using those same conditions this 


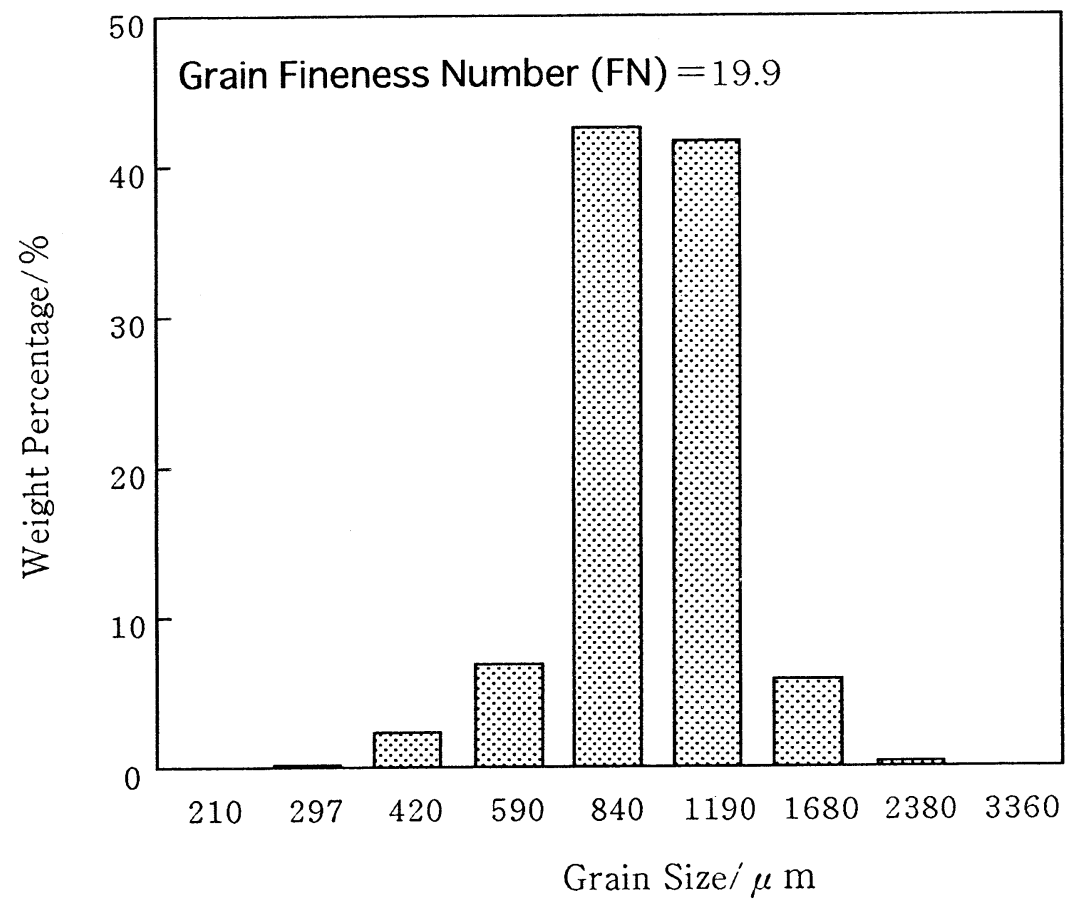

Figure 8. Grain Size Distribution before the Sand Erosion experiment

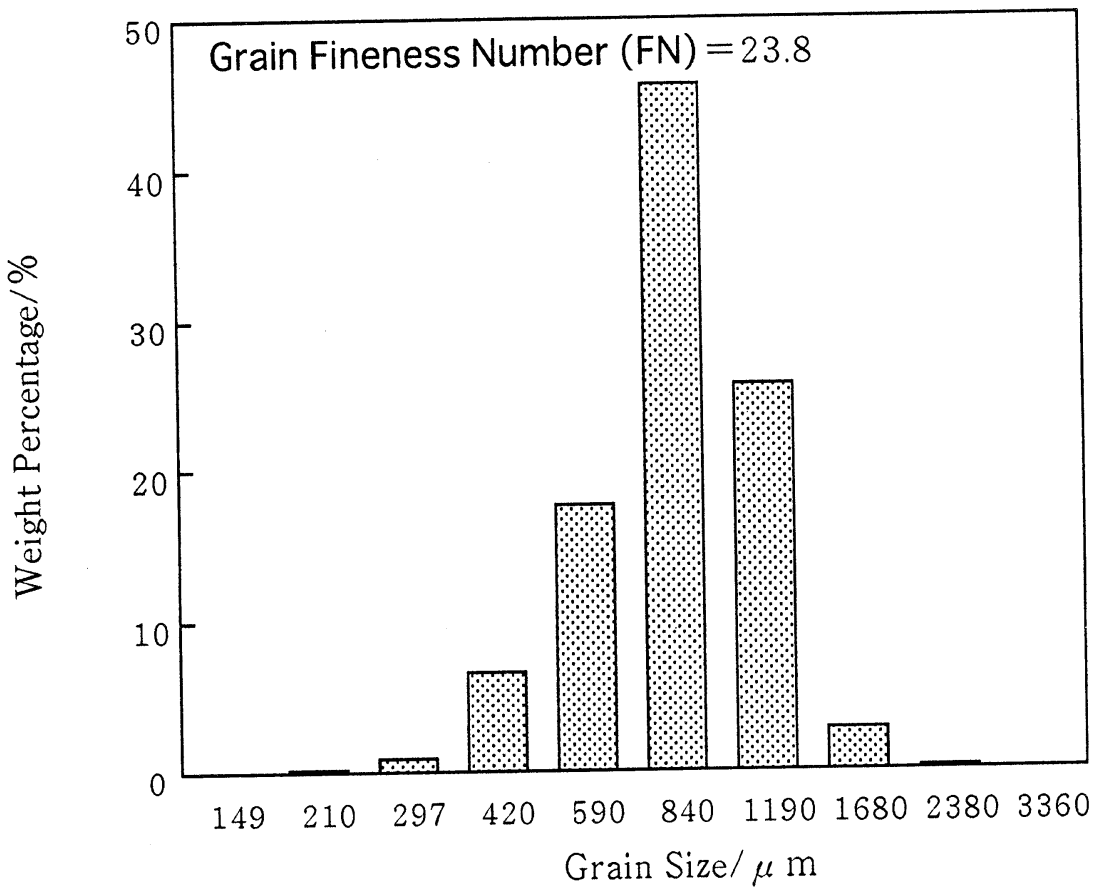

Figure 9. Grain Size Distribution after the Sand Erosion experiment 


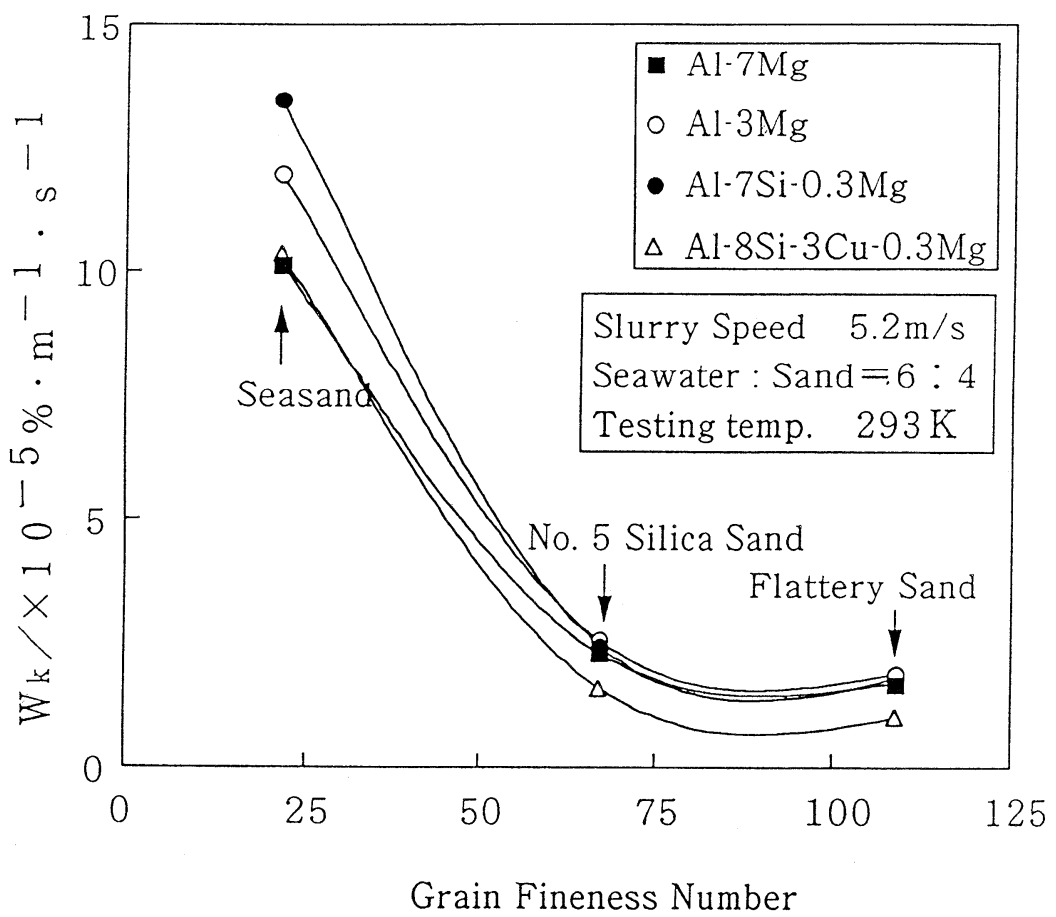

Figure 10. Effect of Grain Size on the Erosion Rate

time with beach sand, 35 hours after the start of the test, the amount of weight loss approached $50 \%$, and the shape of the test specimen varied greatly. Due to this, the slurry speed is lowered to $5.2 \mathrm{~m} / \mathrm{s}(660 \mathrm{rpm})$ and the testing time shortened to 35 hours. Also, data on the erosion rate versus the grain size after a 35-hour test period is summarized on Figure 10. Since the grain size has a significant effect on the erosion rate, the relationship of both axes of graph is considered. From here, the erosion rate may be defined as :

$$
\mathrm{W}_{\mathrm{k}}=\mathrm{k}_{\mathrm{b}} / \mathrm{FN}^{\mathrm{m}}
$$

where $\mathrm{FN}$ : grain fineness number

$$
\mathrm{m}: \text { index number }(\mathrm{m} \fallingdotseq 1-1.5)
$$

\section{3-6. Effect of Sand to Water Ratio on the Erosion Rate of Aluminum Alloys}

Ordinarily, on a moving marine vessel, the propeller rotates at a speed of $3000 \mathrm{rpm}$. As the vessel approaches the shore, the amount of sand increases and the actual propeller speed is not clearly known. From this, the slurry speed is fixed at $3.9 \mathrm{~m} / \mathrm{s}(500 \mathrm{rpm})$, the effect of the amount of sand (sand-to-water ratio) on the sand erosion resistance was investigated.

The sand-to-water ratio is changed from $0 \%$ to $40 \%$. From this, if the sand-to-water ratio is $0 \%$, there effectively is no amount of weight loss, therefore at a sand-to-water ratio of $0 \%$, the amount of weight loss is $0 \%$. Eliminating the $0 \%$ sand-to-water ratio data therefore gives a summary graph shown on Figure 11. From these results, at a large sand to water ratio, the sand erosion resistance of $\mathrm{Al}-7 \mathrm{Mg}$ is the best. A comparative result, still using a slurry speed of $9.3 \mathrm{~m} / \mathrm{s}$ (960 


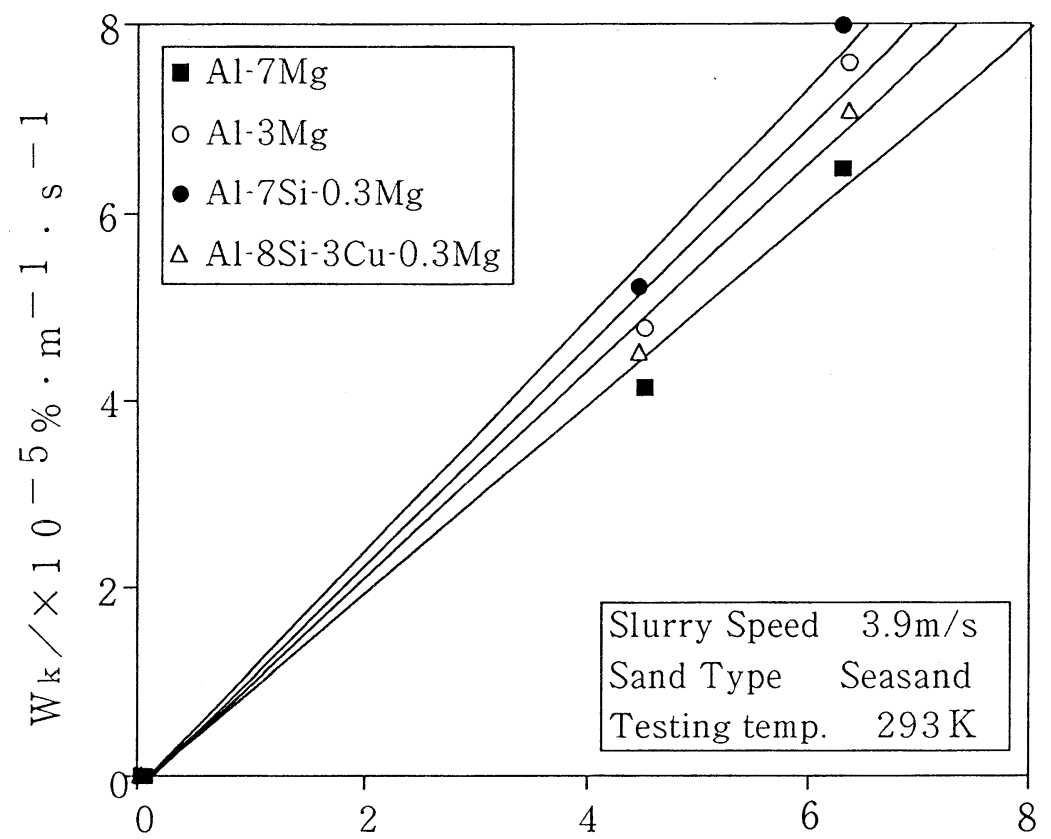

Square Root of Sand to Water Ratio $/(\%)^{0.5}$

Figure 11. Effect of Sand-to-Water Ratio on Erosion Rate

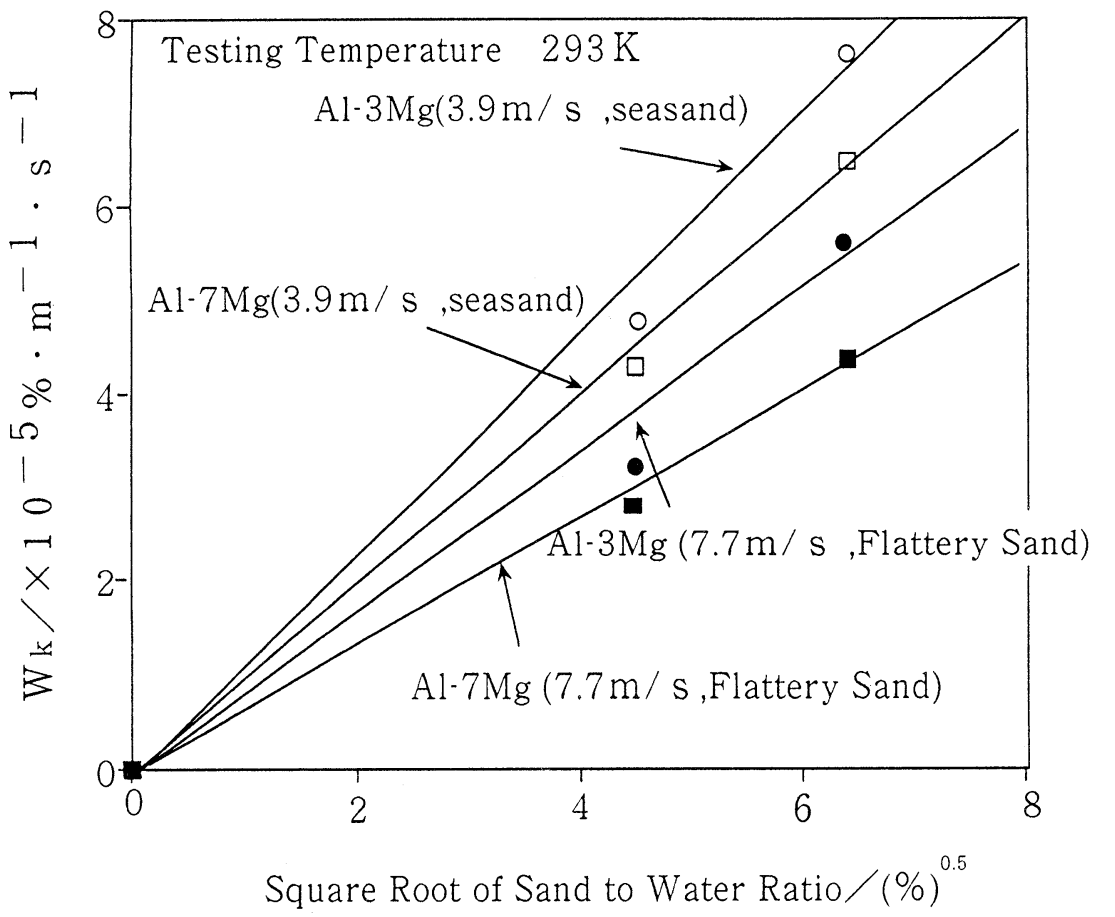

Figure 12. Effect of Sand-to-Water Ratio on Eroson Rate (Comparative) 
rpm) but now using flattery sand is shown in Figure 12. From here, the erosion rate is proportional to the square root of the sand-to-water ratio, as may be shown in formula form as follows :

$$
\mathrm{W}_{\mathrm{k}}=\mathrm{k}_{\mathrm{c}} \cdot \mathrm{p}^{1 / 2}
$$

where $\mathrm{p}:$ sand-to-water ratio

$$
\mathrm{k}_{\mathrm{c}} \text { : constant }
$$

\section{3-7. Effect of Temperature on the Erosion Rate}

The temperature value of $273 \mathrm{~K}$ was used in the experiment since that is the prevailing temperature during warm seasons; however, the seawater temperature during cold seasons must also be considered. With this, a sand erosion test run was done at a test temperature of $280 \mathrm{~K}$. The results of this test is shown in Figure 13 and a comparison with the $273 \mathrm{~K}$ data is shown in Figure 14 . As a result, the amount of weight loss decreased by $2-4 \%$; however, comparing this with the effect of the other factors, temperature does not play a major role.

\section{3-8. Factors affecting Erosion Rate}

From the measured results, the three major factors affecting erosion rate includes slurry speed, grain size, and the sand-to-water ratio. From this, the erosion rate can be closely approximated by :

$$
\mathrm{W}_{\mathrm{k}}=\mathrm{k} \cdot \mathrm{p}^{1 / 2}\left(\mathrm{~V}^{\mathrm{n}} / \mathrm{FN}^{\mathrm{m}}\right)
$$

where $\mathrm{p}:$ sand-to-water ratio

$$
\mathrm{V}: \text { slurry speed }
$$

$\mathrm{FN}$ : grain size

$\mathrm{k}$ : constant $\left(1.1 \times 10^{-5} \sim 1.0 \times 10^{-4} \mathrm{~m}^{-2}\right)$

$\mathrm{n}:$ index number $(\mathrm{n} \fallingdotseq 2-4)$

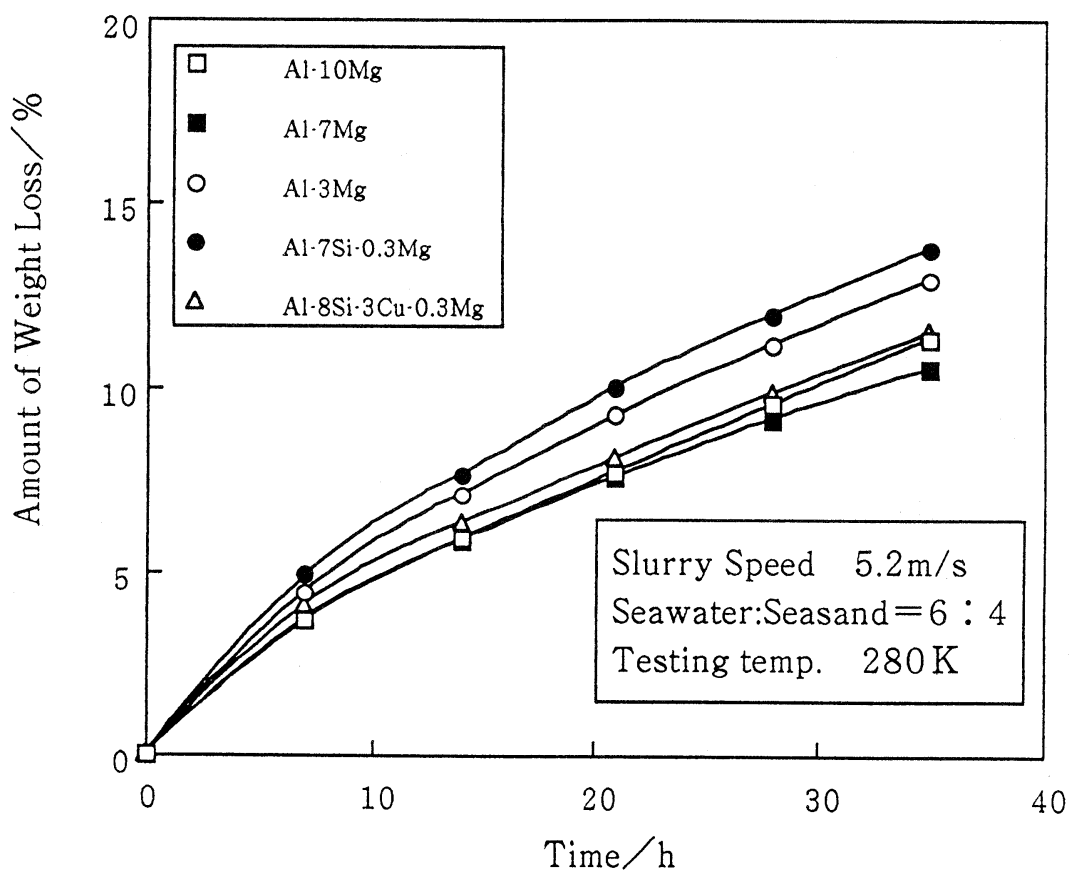

Figure 13. Amount of Weight Loss over a given time in cold temperature 


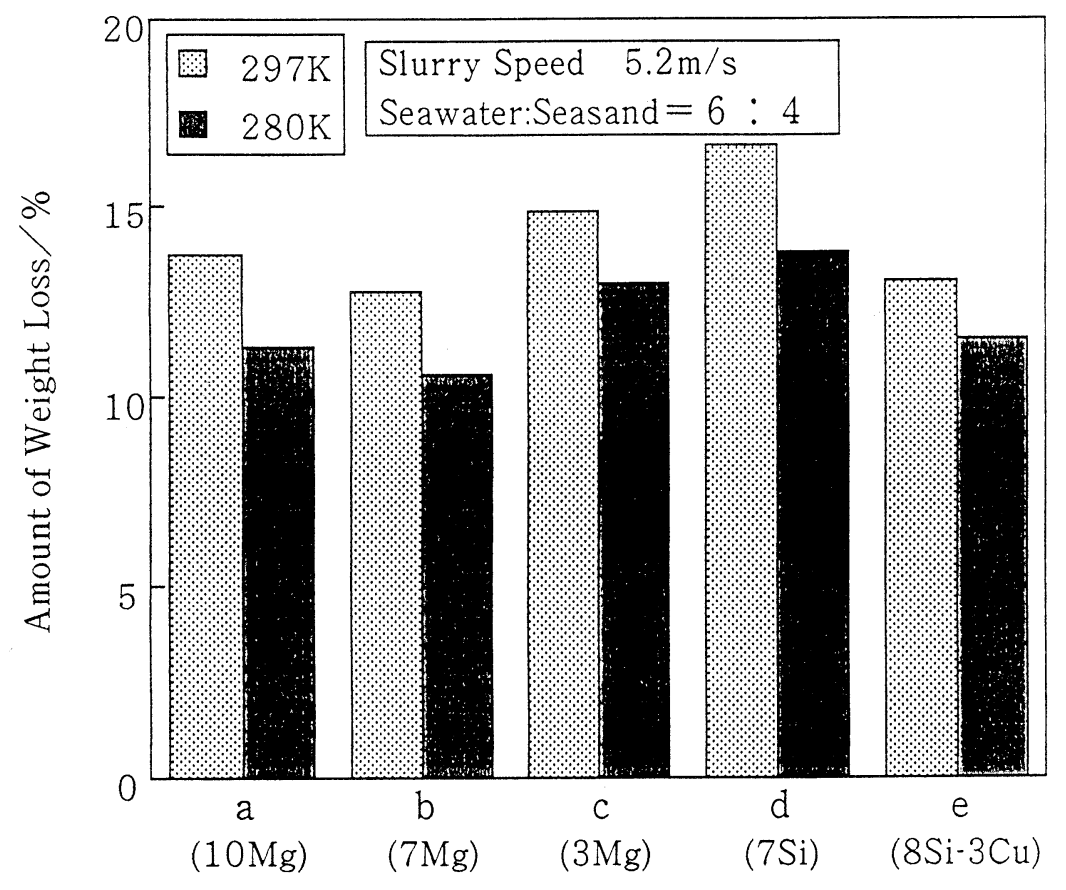

(a)Al-10Mg, (b)Al-3Mg, (c)Al-3Mg, (d)Al-7Si-0.3Mg, (e)Al-8Si-3Cu-0.3Mg

Figure 14. Effect of Temperature on the Amount of Weight Loss

$$
\mathrm{m}: \text { index number }(\mathrm{m} \fallingdotseq 1-1.5)
$$

\section{3-9. SEM Observations of the Erosion Surface}

In doing the observation of the erosion surface after the sand erosion experiment, an area showing the erosion mechanism was looked for. However, as shown in Figure 15, no significant difference within the surfaces can be seen. It cannot be differentiated in which part (phase), wear started. This does not imply that there is something wrong in the proposed erosion mechanism, only that the conditions used in the present experiment for the particular aluminum alloys are so severe.

\section{3-10. Effect of Chemical Composition on the Micro-Vickers Hardness of the Aluminum Alloy}

The effect of chemical composition on the micro-Vickers hardness of the aluminum alloy is shown in Figure 16. In Al-Mg alloys, the hardness increases as the magnesium content increases; however, in actual measurements there is not much difference between $7 \% \mathrm{Mg}$ and $10 \% \mathrm{Mg}$. Also, between the Al-Si-Mg and the Al-Si-Cu-Mg alloy, an increase in silicon content and the presence of copper increases the hardness.

\section{3-11. Areas for Further Study}

From this, within the scope of the present experiment, the effect of corrosion has not been thoroughly considered. While again, reviewing the results of section 3-10 wherein the effect of hardness was investigated (Figure 16), the hardness of $\mathrm{Al}-7 \mathrm{Mg}$ and $\mathrm{Al}-8 \mathrm{Si}-3 \mathrm{Cu}-0.3 \mathrm{Mg}$ is more or less the same, this again still warrants further review. Next, the difference in the micrograph is examined. An $\mathrm{Al}-\mathrm{Mg}$ alloy is basically a solution interphase whereas an Al-Si-Mg alloy is a crystal phase. From 
Seawater: Seasand $=10: 0$
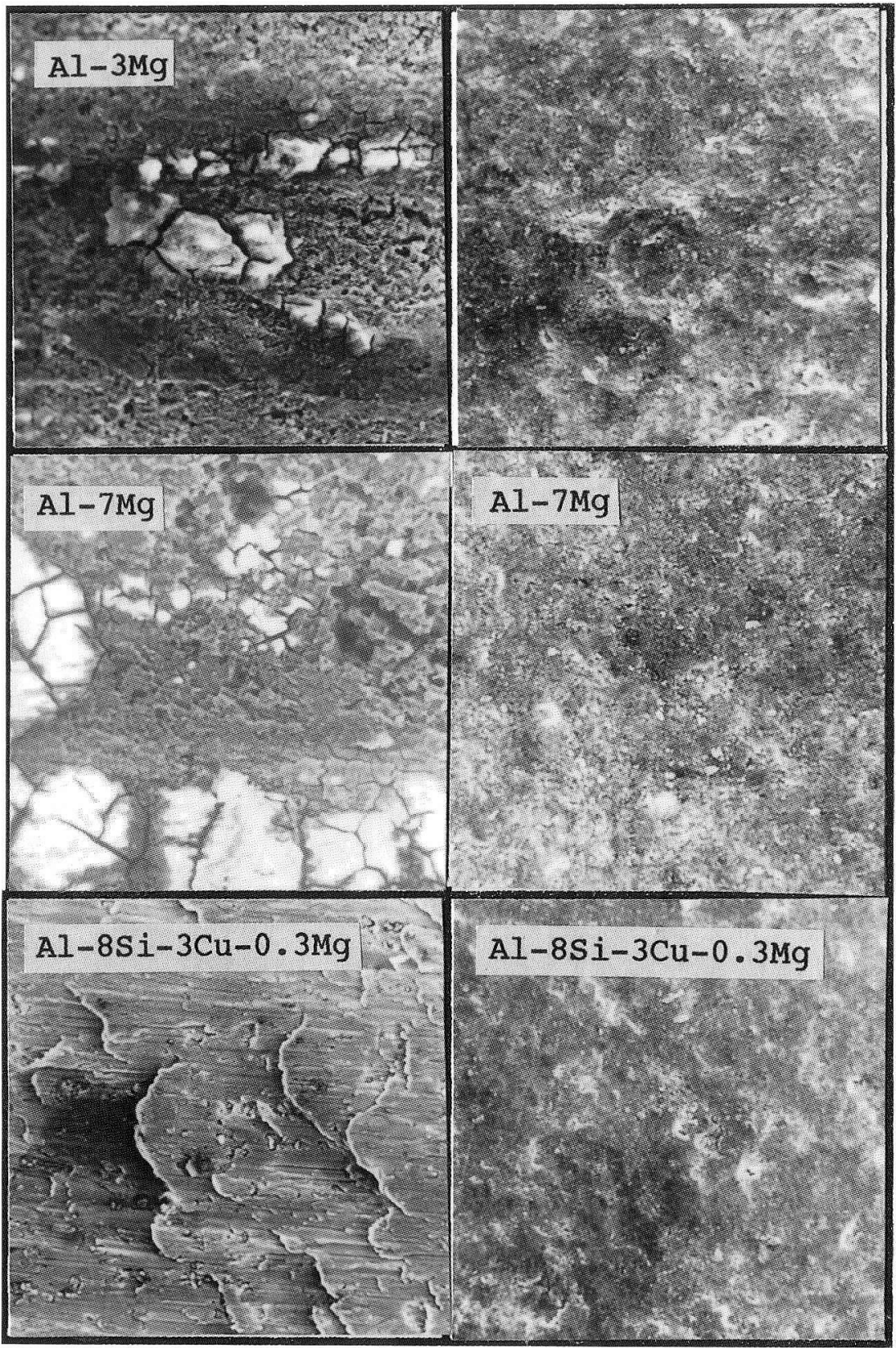

Slurry Speed $3.9 \mathrm{~m} / \mathrm{s}$

Type of Sand Seasand

Testing Temperature 293K

Figure 15. Effect of Sand-to-Water Ratio on the Erosion Surface 


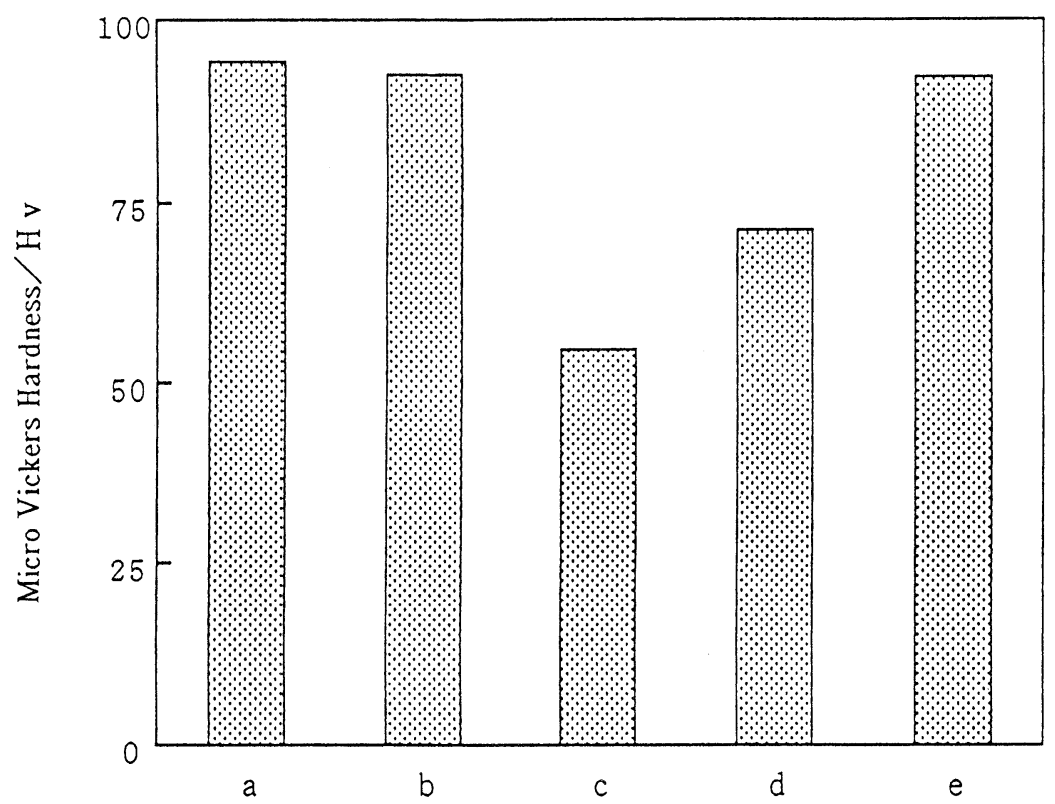

(a)Al-10Mg, (b)Al-7Mg, (c)Al-3Mg, (d)Al-7Si-0.3Mg, (e)Al-8Si-3Cu-0.3Mg

Figure 16. Effect of Composition on the MicroVickers Hardness

this, to clearly differentiate the erosion phases using an SEM photograph as shown in Figure 15 is met with high difficulty. To further establish the erosion using this method was not attained.

\section{CONCLUSIONS}

Working on the given conditions, the results of the sand erosion experiment on the five (5) representative aluminum alloys give rise to the following :

(1) In Al-Mg alloys, magnesium has an effect on the mechanical property of the hard phase ; thereby with a concentration of until 7\%, it improves the sand erosion resistance.

(2) The major factors affecting erosion rate includes slurry speed, grain size and the sand-towater ratio. There is no significant effect made by temperature. Within the three major factors given, a quantitative relationship given by the formula below was derived.

$$
\mathrm{W}_{\mathrm{k}}=\mathrm{k} \cdot \mathrm{p}^{1 / 2}\left(\mathrm{~V}^{\mathrm{n}} / \mathrm{FN}^{\mathrm{m}}\right)
$$

where $\mathrm{Wk}$ : erosion rate

$$
\begin{aligned}
\mathrm{p} & : \text { sand-to-water ratio } \\
\mathrm{V} & : \text { slurry speed } \\
\mathrm{FN} & : \text { grain size } \\
\mathrm{k} & : \text { constant }\left(1.1 \times 10^{-5} \sim 1.0 \times 10^{-4} \mathrm{~m}^{-2}\right) \\
\mathrm{n} & : \text { index number }(\mathrm{n} \fallingdotseq 2-4) \\
\mathrm{m} & : \text { index number }(\mathrm{m} \fallingdotseq 1-1.5)
\end{aligned}
$$




\section{References}

[1] MATSUJIRO HAMAZUMI : "Hitetsu Kinzoku oyobi Goukin", 131, 1972, Tokyo, Uchida Rakuho Shinsya.

[2] JAPAN SOCIETY OF CORROSION ENGINEERING : "Erojyon to Korojyon", 186, 1987, Tokyo, Shokabo.

[3] TAKAYOSHI HASHIGUCHI : "Kinzoku Kogaku Souzai 9 Zairyohen II Hitetsu Kinzoku Zairyo", 102, 1959, Tokyo, Asakura Shoten.

[4] THE JAPAN INSTITUTE OF METALS : "Hitetsu Zairyo Genzai no Kinzokugaku Zairyohen 5", 96, 1987, Tokyo, The Japan Institute of Metals.

[5] FOUNDRY TECHNOLOGY COURSE EDITION : "Futsu Imono", 249, 1968, Tokyo, Nikkan Kojo Shinbunsha. 